\title{
MIDAS
}

Museus e estudos interdisciplinares

$3 \mid 2014$

Varia e dossier temático: "Museos y participación biográfica"

\section{Entre a criação e a exposição: o museu como ateliê do artista. Breve introdução ao tema}

Between creation and exhibition: the museum as artist's studio. Introduction to the theme

\section{Teresa Azevedo}

\section{(2) OpenEdition Journals}

\section{Edição electrónica}

URL: http://journals.openedition.org/midas/589

DOI: $10.4000 /$ midas.589

ISSN: 2182-9543

\section{Editora:}

Alice Semedo, Paulo Simões Rodrigues, Pedro Casaleiro, Raquel Henriques da Silva, Ana Carvalho

\section{Refêrencia eletrónica}

Teresa Azevedo, «Entre a criação e a exposição: o museu como ateliê do artista. Breve introdução ao tema », MIDAS [Online], 3 | 2014, posto online no dia 09 junho 2014, consultado no dia 20 abril 2019 URL : http://journals.openedition.org/midas/589; DOI : 10.4000/midas.589

Este documento foi criado de forma automática no dia 20 Abril 2019.

\section{(c) (i) (9)}

Midas is licensed under a Creative Commons Attribution-NonCommercial-ShareAlike 3.0 International License 


\section{Entre a criação e a exposição: o museu como ateliê do artista. Breve introdução ao tema ${ }^{1}$}

Between creation and exhibition: the museum as artist's studio. Introduction to the theme

Teresa Azevedo

\section{Introdução: a morte do ateliê?}

1 Tradicionalmente, as obras de arte seguem um percurso mais ou menos estabelecido: o artista cria a obra na privacidade do seu ateliê; ela será depois exposta num museu ou galeria, podendo ser eventualmente adquirida para uma coleção institucional ou privada. O papel do artista neste processo será o de produtor de um objeto artístico e neste sentido facilmente se percebe a importância do ateliê enquanto espaço privilegiado de criação artística. Não é por acaso que muitas vezes o ateliê é evocado como o substituto físico da mente do artista (Wood 2005, 158), cujo acesso é uma oportunidade privilegiada de contactar, em primeira mão, com as suas intenções, inspirações e processo de trabalho. E, obviamente, todas as pistas aí recolhidas revelar-se-ão uma mais-valia para a compreensão da obra exposta. Assim se criou uma imagem romantizada, mítica até, do ateliê do artista, que em grande parte talvez ainda hoje se mantenha. ${ }^{2}$

2 Foi contra esta ideia tradicional do processo artístico, no qual o artista seria um mero criador de objetos estéticos que perderiam a sua verdade e caráter quando saíam do ateliê para serem expostos noutro lugar qualquer, que Buren ${ }^{3}$ proclamou, em 1971, a «extinção» do ateliê: "The art of yesterday and today is not only marked by the studio as an essencial, often unique, place of production: it proceeds from it. All my work proceeds from its extinction» (59). No entanto, em vez de «extinção» talvez se possa antes falar, como defende Hoffmann, da «expansão» da noção de ateliê:

With the shifts and changes in artistic production over the last century, the death

of the studio has been proclaimed at numerous times, especially during the heyday 
of conceptual art in the late 1960s and 1970s, when the concept of 'art as idea' penetrated more traditional artistic production, suggesting a move away from the 'hand' of the artist, the physical creative act, and perhaps any consideration of skill at all. The moment when the grip of traditional media such as painting and sculpture weakened, the studio in its classic sense began to disappear as well. While many artists indeed do not have typical studios any more, most do maintain some kind of working space. Instead of talking about the end of the studio, perhaps we can speak of the expanded concept of the studio [...]. (2012,12-13)

O próprio Buren, que juntamente com Robert Smithson, Bruce Nauman ou Andy Warhol, entre outros, é considerado um dos protagonistas do que se convencionou chamar uma era pós-estúdio4, acabará por afirmar em 1988 que o seu ateliê é, de facto, o local onde ele próprio se encontra (Davidts e Paice 2009, 80), contestando assim a visão e a identidade tradicional do ateliê, o que abriu portas à expansão do conceito para modelos alternativos. E, como refere Kennedy, essa contestação do ateliê, feita de modo diverso por cada artista, levou por sua vez a uma «reavaliação das relações tradicionais existentes entre o artista e o museu» (2007, 25-26). Exemplo claro é mais uma vez Buren que, trabalhando especificamente em museus e galerias de arte, acabou por «converter o museu no seu ateliê, uma e outra vez»:

Since every artwork, Buren realized, is made on site, a separate workspace became an obsolete, useless, even absurd relic. [...] He exchanged the fixed workspace of the studio for a moveable, mobile spatial condition, an artistic situation of work. Ever since then, his studio has coincided with the institutional context in which he operates. (Davidts e Paice 2009, 67)

O ateliê do artista enquanto «espaço e condição» (Jacob e Grabner 2010, ix) é um tópico bastante fértil, tanto para a história da arte como para a curadoria e para a museologia. Através do seu estudo podem explorar-se diversas relações dinâmicas com os dispositivos inerentes à criação, produção, exposição e musealização da arte contemporânea, o que desde logo revela a complexidade e a pertinência do tema. ${ }^{5}$

Das publicações dedicadas ao assunto, destaca-se o texto seminal The Function of the Studio (Buren [1971] 1979), já referido atrás, e que tem o duplo interesse de, sendo escrito por um artista, refletir sobre os pressupostos da arte do seu tempo e explorar o seu reflexo no método e local de criação, acabando por declarar a extinção do ateliê. Em Imagination's Chamber: Artists and Their Studios (Peppiatt e Bellony-Rewald 1983) pela primeira vez a história da arte, desde a antiguidade até ao início dos anos 80, é explorada através da relação com os ateliês de artistas. Por sua vez, o estudo sobre as transformações na arte americana dos anos 60, Machine in the Studio: Constructing the Postwar American Artist (Jones 1996), analisa a transformação do conceito de ateliê operada a partir dessa década, sendo um trabalho pioneiro e amplamente citado.

6 Apesar de ser um conceito presente desde sempre no processo de criação artística, é sobretudo a partir de 2000 que começam a surgir importantes estudos e antologias sobre os ateliês de artistas, refletindo um crescente interesse por este tema e que, de certo modo, contraria o pressuposto da sua morte ou extinção. Em Inventions of the Studio, Renaissance to Romanticism (Cole e Pardo 2005), destaca-se sobretudo o primeiro capítulo, no qual os autores refletem sobre as origens do termo ateliê (studio). The Studio (Hoffmann e Kennedy 2007) decorre da exposição com o mesmo nome realizada na Dublin City Gallery the Hugh Lane, em 2006, sendo importante a revisão que Buren faz do seu artigo de 1971. Tomando o ateliê sobre diferentes perspetivas, antologias como The Fall of the Studio: Artists at Work (Davidts e Paice 2009), The Studio Reader: On the Space of Artists (Jacob 
e Grabner 2010), The Studio (Hoffmann 2012) e Hiding Making - Showing Creation: The Studio from Turner to Tacita Dean (Esner, Kisters, e Lehmann 2013), refletem sobre o ateliê, a sua função e condição na arte contemporânea, compilando importantes textos de artistas, historiadores e críticos de arte, curadores e museólogos, e que revelam, assim, a multiplicidade de disciplinas através das quais este tema pode ser abordado.

Especificamente sobre as dinâmicas entre o museu e o ateliê, destacam-se Studio and Cube: On the Relationship Between Where Art is Made and Where Art is Displayed (O'Doherty 2008, 12) e The Studio in the Gallery? (Wood 2005), texto de Wood publicado numa antologia dedicada ao espaço do museu e às suas transformações (McLeod 2005).

Entendido assim o ateliê enquanto um conceito que pode não corresponder simplesmente a um espaço físico, mas que se expande para além dele e representa o processo pessoal de criação artística e de produção de significado, facilmente se percebe que atualmente o ateliê pode ser tão variado como uma simples mesa de café ou da cozinha, uma página da internet, um muro na rua, uma sala da galeria ou museu...

\section{O museu como ateliê do artista}

Expandido o seu conceito, facilmente se compreende que, assim como existem variados tipos de ateliês existem também diversas leituras e interpretações que se podem fazer a partir (e através) deles. $O$ ateliê pode ser a inspiração e o tema principal da obra, através de representações dele mesmo (p. ex. nas pinturas 0 Artista no seu Atelier, c. 1629, de Rembrandt, O Ateliê do Artista, 1855, de Courbet ou L'Atelier Rouge, 1911, de Matisse); o ateliê pode ser a base de estudos sobre questões de originalidade, de autenticidade e de produção ${ }^{6}$, nomeadamente em relação à autoria e direitos autorais relacionados com a produção no ateliê (um exemplo recente que pode levar a pensar estas questões é o caso de Damien Hirst, que desde 2012 disponibiliza acesso livre online à atividade no seu ateliê, onde dois assistentes realizam uma obra ${ }^{7}$ ); o conteúdo e os vestígios do ateliê podem ser estudados e inventariados de modo a melhor documentar, compreender e preservar a obra de um artista (de que é exemplo o levantamento arqueológico e o inventário de todo o conteúdo do ateliê de Francis Bacon); ; ou o ateliê pode ainda ser estudado em função da sua localização e das relações intrínsecas do lugar com a obra do artista ou vice-versa (p. ex. o jardim de Giverny de Monet, e o terceiro ateliê do artista aí mandado construir especificamente para pintar a série monumental Les Nymphéas).

Variados outros exemplos de abordagem ao tema do ateliê do artista podiam ser referidos, mas no âmbito deste artigo interessa agora analisá-lo sobre o ponto de vista das relações possíveis com o museu.

11 Como já foi referido, nos últimos anos tem sido notório um crescente interesse teórico no tema do ateliê de artista, interesse esse que se reflete também no meio institucional, sobretudo na organização de exposições que exploram diferentes abordagens ao ateliê. Destacam-se Close Encounters: the Sculptor's Studio in the Age of the Camera, realizada em 2001 no Henry Moore Institute (Leeds); Mapping the Studio, em 2006 no Stedelijk Museum (Amesterdão); The Studio, também em 2006 na Hugh Lane Gallery (Dublin); Ateliers: L'artistes et ses Lieux de Création dans les Collections de la Bibliothèque Kandinsky, em 2007 no Centre Georges Pompidou (Paris); Picturing the Studio, em 2009-2010, na School of the Art Institute de Chicago; ou Production site. The artist's studio inside out, realizada em 2010 no Museum of Contemporary Art, em Chicago. Para além de mostrarem as diferentes 
possibilidades de investigação que se podem desenvolver a partir do tema ${ }^{9}$, estas exposições confirmam também que o museu pode ser um lugar de reflexão artística e crítica sobre um assunto que, tradicionalmente, lhe seria exterior.

Wood, no seu texto The Studio in the Gallery? (2005), parte precisamente de uma destas exposições, Close Encounters: the Sculptor's Studio in the Age of the Camera ${ }^{10}$, que ele próprio comissariou para analisar o "ateliê no museu». Segundo o autor, a exposição levantou duas importantes questões sobre os problemas de apresentar e representar o ateliê no museu, questões essas que Wood assume como principais linhas de análise e que serão neste texto também apresentadas enquanto base de estudo.

13 A primeira refere-se às reconstruções do ateliê - Studio Reconstructions (Wood 2005, 163165) - e remete para uma reconstrução ou mesmo para uma deslocação efetiva e material do ateliê para o museu, sobretudo após a morte do artista. Através desta opção, necessariamente histórica e retrospetiva, o ateliê do artista é considerado, no seu conjunto material, como uma espécie de objeto arqueológico, passando a pertencer assim ao mundo institucional da arte. Nestas reconstruções e deslocações do ateliê do seu lugar de origem para um espaço museológico, numa tentativa de dar a ver mais profundamente o processo de trabalho do artista, obviamente que muito do significado original se perde e o ateliê surge descaracterizado. Tratando-se, muitas vezes, dos materiais originais usados pelo artista e ainda que se tente reconstruir o mais fielmente possível a sua distribuição no espaço, o facto de ter sido transferido para outro espaço - e um espaço público (o museu) - confere-lhe novo significado.

Uma referência seminal neste ponto é o escultor Constantin Brancusi, um dos primeiros artistas a demonstrar ele próprio a consciência da importância do espaço de criação como lugar privilegiado de exposição para uma compreensão total da obra, sendo um caso estudado e referido por diversos autores, sobretudo devido às questões levantadas com as sucessivas reconstruções do seu ateliê, que desde 1997 se encontra no exterior do Centre Georges Pompidou. Por exemplo, em 1971, Buren refere que para si Brancusi é o único artista que lidou de modo inteligente com o sistema de musealização e as suas consequências para a leitura da obra de arte, opondo-se a ele ao não permitir que o seu trabalho fosse exposto de acordo com os critérios de um qualquer curador. Buren refere ainda que Brancusi foi o único artista que, de modo a preservar a relação entre a obra e o seu lugar de criação (para Buren, uma relação primordial), se atreveu a mostrar os seus trabalhos no exato lugar onde eles teriam sido criados ([1971] 1979, 56-58), configurando ele próprio a exposição das obras no ateliê, onde deveriam ser vistas e conservadas.

Um caso mais recente é o ateliê de Francis Bacon, reconstruído na Dublin City Gallery The Hugh Lane e aí aberto ao público desde maio de 2001, numa nova ala do museu construída propositadamente para o albergar. Ao contrário de Brancusi, Bacon não deixou qualquer indicação explícita de desejar manter o seu ateliê conforme estivesse após a sua morte. No entanto, o ateliê tornou-se uma imagem marcante da obra de Bacon, existindo várias fotografias do espaço e descrições do mesmo, de modo que a sua deslocação para a Hugh Lane Gallery ${ }^{11}$, um dos mais importantes museus de arte moderna e contemporânea da Irlanda, foi feita com grande expectativa. Uma equipa de arqueólogos e historiadores de arte estudou e catalogou todo o conteúdo do ateliê de Bacon tal como o artista o deixara em 1992, de forma a reconstruí-lo o mais fielmente possível no novo espaç ${ }^{12}$. Por sua vez, o inventário realizado, que documenta todo o conteúdo do ateliê e elucida sobre a profundidade e a variedade de recursos aí existentes, está disponível para consulta numa galeria interativa à saída do museu. 
16 Estas reconstruções ou deslocações do ateliê, apesar de se instaurarem como importantes polos atrativos de visitantes para os museus que as albergam, levantam várias questões que atravessam áreas como a museologia, a curadoria ou a história da arte. A musealização destes espaços implica necessariamente preocupações de preservação e salvaguarda do que é exposto, de maneira que estas reconstruções (e os exemplos de Brancusi e Bacon são claros nisso) não permitem ao visitante uma experiência real, pois, na maior parte das vezes, apenas se tem acesso a elas através de vidros que não permitem a passagem para o interior, mas que levam antes a uma experiência voyeurista. Muitas vezes, o facto de esta deslocação para o museu se dar após a morte do artista, dificulta a aproximação à sua vivência original como local de inspiração, criação e produção artística. De qualquer modo, este tipo de relação entre o ateliê e o museu, com todas as implicações e dificuldades que lhe são inerentes, pode por isso mesmo revelar-se como uma importante linha de análise crítica, útil para a compreensão da figura do artista e do seu processo de trabalho.

17 A segunda linha de análise, designada por Wood como instalações do ateliê - Studio Installations $(2005,165-168)$ - diz respeito ao modo como muitos artistas contemporâneos exploram a noção de ateliê no espaço do museu, não só como um ambiente material e físico, mas sobretudo como uma espécie de reconstituição mental do seu processo e lugar de trabalho. Segundo esta perspetiva, através da instalação no museu de elementos criados e selecionados pelo próprio, o artista cria um ambiente simbólico que tenta refletir (e dar a refletir) sobre o seu próprio modo de trabalho e de pensamento. Como refere Wood, as «instalações» do ateliê, ao contrário das «reconstruções», são contemporâneas e antecipatórias $(2005,163)$ : é o próprio artista que conscientemente e através de sinais metafóricos por si escolhidos, encena o seu lugar de trabalho ou o seu processo mental de criação artística, normalmente pessoais e privados, no espaço público do museu. Caberá depois aos visitantes a descodificação desses sinais usados pelo artista para dar a ver o seu lugar e processo de trabalho.

Um exemplo pertinente é o de Bruce Nauman, que em vez de abolir o ateliê da sua prática, como fizeram muitos artistas da sua geração, transformou-o de acordo com os seus próprios parâmetros. Fascinado pelo ateliê vazio e por todas as questões sobre o que é um artista e o que faz ele nesse espaço, e consequentemente sobre o que é uma obra de arte, nos finais dos anos 1960 Nauman iniciou uma série de filmes que registavam simples atividades suas no ateliê (p. ex. Playing a Note On the Violin While I Walk Around the Studio, 1967-68). Mais recentemente, frustrado por ir para o ateliê e não ter ideias novas para trabalhar, Nauman decidiu usar o que tinha imediatamente disponível, que naquele momento (em 2000 no seu ateliê em Galisteo, Novo México) era uma grande infestação de ratos. Tendo também disponível uma câmara com infravermelhos, decidiu deixá-la ligada durante a noite quando o ateliê estava vazio. O resultado dessas filmagens foi a obra Mapping the Studio I (Fat Chance John Cage), 2000 (exposta pela primeira vez, em 2001, no DIA Art Foundation, em Nova Iorque) constituída pela instalação no museu de projeções vídeo e várias faixas de som que documentam a atividade noturna do ateliê do artista, transpondo-o e cruzando-o desse modo com o espaço de exposição. Neste caso, como refere Marks (2009), em vez de se espreitar por um vidro ou janela para uma reconstrução do ateliê de Bruce Nauman, como acontece com as reconstruções do ateliê mencionadas atrás, o visitante do museu é antes «transportado» para o seu interior através da instalação de mecanismos que o envolvem física ou simbolicamente: 
The artist's activity is replaced by the recording equipment, left to its own devices; and by the audience, left to fend for themselves, for the work places us (illusionistically, physically, psychically) in the studio where Nauman ought to be [...]. (115-116)

19 Ao apresentar estes filmes no museu, Nauman transfere a experiência privada do seu ateliê para o espaço público e institucional do museu, relacionando intrinsecamente os dois dispositivos, através da presença essencial dos visitantes (Reijnders 2013, 150).

Estas instalações do ateliê, de que Nauman é apenas um exemplo, como são normalmente pensadas e criadas pelos próprios artistas - são, no fundo, obras de arte sobre o ateliê criadas especificamente no museu - têm a particularidade de se poderem constituir como críticas à bagagem histórica que os conceitos de ateliê e museu carregam consigo ${ }^{13}$, ao mesmo tempo que podem também, apoiadas por um enquadramento institucional, fazer uma releitura do que são hoje os espaços de criação e de apresentação da arte contemporânea.

21 Às duas categorias propostas por Wood (2005) está inerente uma noção efetiva de ateliê: na reconstrução do ateliê faz-se uma transposição/deslocação física do lugar de criação artística, mesmo que o objetivo seja desvendar o processo mental por trás da produção; e nas instalações do ateliê é o próprio artista que procura realizar uma transposição simbólica do seu processo de trabalho. Em ambos os casos, o que se pretende alcançar é uma vivência no museu do espaço efetivo e afetivo, seja ele formal ou mental, de criação do artista. A ideia do ateliê enquanto espaço privilegiado de criação artística continua presente: o que se deu foi a sua expansão de um lugar privado, de acesso restrito (tradicionalmente) para um lugar público.

22 Para além das categorias de Wood (2005), e assumindo-se o ateliê dentro de um campo alargado que o pode inserir no espaço do museu, proponho uma terceira abordagem: a ideia de mobilidade aplicada ao ateliê. Uma das principais características da arte contemporânea é o nomadismo que lhe está implícito. Este nomadismo não se refere apenas às obras que, cada vez mais e de um modo mais fácil e rápido circulam por vários locais para diferentes exposições. Ele implica-se também, necessariamente, na figura do artista, cada vez mais solicitado para criar obras site-specific ou para acompanhar a montagem de uma exposição. Neste sentido, se o conceito de ateliê se expandiu para abarcar novos modelos e outros modos de entender o lugar (físico, mental, afetivo) de criação artística, pode-se então assumir que, se o ateliê está sempre inerente à prática do artista e se este se desloca para trabalhar noutro local, então o ateliê desloca-se com ele. Como já se referiu, a expansão da noção de ateliê - e, com ela, do papel do artista - seguiu de perto a evolução das práticas artísticas que assumem o lugar como parte integrante do trabalho. Kwon explica este processo:

Typically, an artist (no longer a studio-bond object maker, primarily working on call) is invited by an art institution to execute a work specifically configured for the framework provided by the institution (in some cases the artist may solicit the institution with a proposal). Subsequently, the artist enters into a contractual agreement with the host institution for the commission. There follows repeated visits to or extended stays at the site; research into the particularities of the institution and/or the city within which it is located (its history, constituency of the [art] audience, the installation space); consideration of the parameters of the exhibition itself (its thematic structure, social relevance, other artists in the show); and many meetings with curators, educators, and administrative support staff, who may all end up "collaborating" with the artist to produce the work. The project will likely be time-consuming and in the end will have engaged the "site" in a multitude 
of ways, and the documentation of the project will take on another life within the art world's publicity circuit, which will in turn alert another institution for another commission. (2002, 51-52) contemporânea como um ateliê ou laboratório experimental, onde o processo é valorizado em detrimento da obra finalizada e fechada. Um exemplo recente é a obra Seed Stage de Corin Hewitt, instalada no Whitney Museum of American Art (de 3 de outubro de 2008 a 4 de janeiro de 2009). No espaço do museu foi criada uma estrutura retangular que albergava um espaço de trabalho para o artista. Apenas os cantos dessa estrutura eram abertos e através deles os visitantes podiam espreitar para a atividade do artista no interior. Como refere Rodenbeck, esta instalação apresentou-se como uma «rara reconfiguração da relação entre o trabalho do artista no ateliê e o lugar de exposição» $(2010,336)$. Para citar um caso recente em Portugal, refira-se a exposição Casa de Manuel Vieira onde, de fevereiro a abril de 2013, o artista recriou o espaço da sua casa e ateliê na Cordoaria Nacional (Lisboa); decorou-o com a sua própria mobília e objetos, e mudou-se para lá, onde viveu e trabalhou durante o período da exposição. Com estes exemplos se compreende como as tradicionais oposições entre espaço de criação e espaço de exposição são esbatidas e se tornam contínuas (Relyea 2010, 344), permitindo ao visitante uma experiência, à partida, mais próxima do ato e do processo criativos, e simultaneamente abrem portas a novos modos de pensar e explorar a relação entre o ateliê e o museu.

\section{Conclusões}

O museu como ateliê do artista é, como se argumentou, apenas uma das leituras possíveis de entre todas as que o campo expandido do ateliê permite perspetivar. É certo que a maior parte dos artistas, hoje, continua a manter um espaço de trabalho no sentido mais tradicional do termo. Mas é também verdade que, muitas vezes, estendem esse espaço para outros onde trabalham mais especificamente (o museu, o espaço público, a internet). Assim, independentemente do modelo de ateliê, o seu estudo é sempre revelador do processo criativo de um artista. Não é por acaso que os escritos de artistas, as entrevistas ou os filmes com artistas a trabalhar, são muito usados como fontes de acesso primário ao pensamento e ao processo criativo de um artista. Todas essas fontes podem ser encontradas através do estudo do ateliê e dos vestígios e pistas que nele possam existir, e que se revelam essenciais para um mais completo entendimento do corpo de obra de um artista e do seu método de trabalho.

Procurei ao longo deste artigo encadear exemplos da variedade dos modelos de relação entre o ateliê, enquanto espaço de criação, e o museu, enquanto espaço de exposição, e apresentar as possibilidades de reflexão crítica que eles permitem explorar. 
Esta primeira análise geral teve como objetivo sustentar a minha investigação futura com aplicação a casos de estudo nacionais. Pretendo estudar o ateliê enquanto recurso essencial para o entendimento da obra de um artista, e penso que a relação dinâmica com o museu é inevitável e, como se analisou em alguns dos exemplos apresentados, pode elucidar sobre o processo criativo e de produção artística. Simultaneamente, no campo da museologia, entendido transdisciplinarmente ${ }^{14}$, a documentação dos ateliês de artista bem como a sua musealização levantam questões pertinentes que importa continuar a explorar.

\section{BIBLIOGRAFIA}

Bishop, Claire. 2004. “Antagonism and Relational Aesthetics.” October 1 (110): 51-79.

Buren, Daniel. (1971) 1979. “The Function of the Studio.” October 10 (Fall): 51-59.

Cole, Michael Wayne, e Mary Pardo, eds. 2005. Inventions of the Studio, Renaissance to Romanticism. Chapel Hill: The University of North Carolina Press.

Davidts, Wouter, e Kimberly Paice, eds. 2009. The Fall of the Studio: Artists at Work, Antennae. Valiz: Antennae.

Dewdney, Andrew, David Dibosa, e Victoria Walsh. 2013. Post Critical Museology: Theory and Practice in the Art Museum. London: Routledge.

Esner, Rachel, Sandra Kisters, e Ann-Sophie Lehmann, eds. 2013. Hiding Making - Showing Creation: The Studio from Turner to Tacita Dean. Amsterdam: Amsterdam University Press.

Getsy, David J. 2010. "The Reconstruction of the Francis Bacon Studio in Dublin." In The Studio Reader: On the Space of Artists, editado por Mary Jane Jacob, e Michele Grabner, 99-103. Chicago e London: University of Chicago Press.

Hoffmann, Jens, ed. 2012. The Studio. Documents of Contemporary Art Series. London e Cambridge: Whitechapel Art Gallery e The MIT Press.

Hoffmann, Jens, e Christina Kennedy, eds. 2007. The Studio. Dublin: Dublin City Gallery The Hugh Lane.

Hughes, Anthony. 1990. "The Cave and the Stithy: Artists' Studios and Intellectual Property in Early Modern Europe. " Oxford Art Journal 13 (1): 34-48.

Jacob, Mary Jane, e Michelle Grabner, eds. 2010. The Studio Reader: On the space of Artists. Chicago e London: University of Chicago Press.

Jones, Caroline A. 1996. Machine in the Studio: Constructing the Postwar American Artist. Chicago: University of Chicago Press.

Kennedy, Christina. 2007. "Exhibiting the Studio.” In The Studio, editado por Jens Hoffmann, e Christina Kennedy, 23-29. Dublin: Dublin City Gallery The Hugh Lane. 
Kwon, Miwon. 2002. “One Place After Another: Notes On Site Specificity.” In Space, Site, Intervention: Situating Installation Art, editado por Erika Suderburg, 38-63. Minneapolis: University of Minnesota Press.

Marks, MaryJo. 2009. “Seeing Through the Studio: Bruce Nauman.” In The Fall of the Studio, editado por Wouter Davidts, e Kimberly Paice, 94-117. Valiz: Antennae.

McLeod, Susan, ed. 2005. Reshaping Museum Space: Architecture, Design, Exhibitions. London: Routledge.

O'Doherty, Brian. 2008. Studio and Cube: On the Relationship Between Where Art is Made and Where Art is Displayed. New York: Temple Hoyne Buell Center for the Study of American Architecture.

Peppiatt, Michael, e Alice Bellony-Rewald. 1983. Imagination's Chamber: Artists and Their Studios. London: Gordon Fraser.

Reijnders, Frank. 2013. “The Studio as Mediator." In Hiding Making - Showing Creation: The Studio from Turner to Tacita Dean, editado por Rachel Esner, Sandra Kisters, e Ann-Sophie Lehmann, 136156. Amsterdam: Amsterdam University Press.

Relyea, Lane. 2010. "Studio Unbound." In The Studio Reader: On the Space of Artists, editado por Mary Lane Jacob, e Michelle Grabener, 341-349. Chicago e London: University of Chicago Press.

Rodenbeck, Judith. 2010. “Studio Visit.” In The Studio Reader, editado por Mary Lane Jacob, e Michelle Grabener, 336-340. Chicago e London: University of Chicago Press.

Wood, Jon. 2005. “The Studio in the Gallery?” In Reshaping Museum Space: Architecture, Design, Exhibitions, editado por Suzanne McLeod, 158-169. London: Routledge.

\section{NOTAS}

1. O tema aqui abordado insere-se num contexto de investigação mais alargado desenvolvido no âmbito da tese de doutoramento com o título: No Campo Expandido do Ateliê: Dinâmicas do Processo Criativo.

2. Apesar de se situar fora do âmbito deste artigo, é interessante pensar se a expansão do conceito de ateliê terá efetivamente permitido um acesso mais direto ao processo criativo e de trabalho do artista ou se apenas criou uma ilusão desse acesso e o ato criativo se manteve estrategicamente oculto do público. Sobre este assunto, ver a recente publicação Hiding Making Showing Creation. The studio from Turner to Tacida Dean (Esner, Kisters, e Lehmann 2013), entre outras.

3. Buren é um exemplo amplamente citado por vários autores, na medida em que foi um dos primeiros artistas a tomar consciência (e a escrever sobre isso) das alterações que a partir dos anos 1960 se começaram a processar no modo como os artistas viviam e encaravam o ateliê, refletindo sobre este tópico no texto The Function of the Studio (1970-71), atualizado depois em 2006 (The Function of the Studio' Revisited: Daniel Buren in Conversation) (Hoffmann e Kennedy 2007, 104-106).

4. De notar que o termo não era usado por estes artistas e apenas começou a ser usado posteriormente, em consequência das suas práticas que notoriamente se distanciavam da conceção mais tradicional de ateliê enquanto local privilegiado e único para a criação e produção de obras de arte.

5. É interessante, embora fora do alcance deste artigo, pensar sobre o conceito de ateliê sobretudo a partir do século XIX, quando este espaço se separa da oficina (o lugar do trabalho manual, do artesão), e se torna o lugar ideal de inspiração artística. $O$ artista começa então a ser 
associado a um intelectual ou pensador, e o ateliê torna-se o lugar privado, recolhido do mundo exterior, onde cria obras inspiradoras, que só são trazidas a público quando completamente terminadas. Assim se criou uma imagem romantizada do artista e do seu local de trabalho, isolado e inacessível. Sobre este assunto ver os textos de Sandra Kisters e Monika Wagner (Erner, Kisters, e Lehmann 2013, 15-30 e 31-42).

6. Sobre este assunto ver The Cave and the Stithy: Artists' Studios and Intelectual Property in Early Modern Europe (Hughes 1990).

7. http://www.damienhirst.com/live-feed (consultado em janeiro 27, 2014).

8. http://www.francis-bacon.com (consultado em janeiro 27, 2014).

9. A exposição The Studio, na Hugh Lane Gallery, por exemplo, foi acompanhada de um simpósio que procurou refletir precisamente sobre o papel do ateliê na produção artística contemporânea, bem como por uma publicação sobre o tema: The Studio (Hoffman e Kennedy 2007).

10. Realizada no Instituto Henry Moore, em Leeds, de 25 de setembro de 2001 a 6 de janeiro de 2002.

11. Bacon viveu e trabalhou no mesmo ateliê (7 Reece Mews, South Kensington), em Londres, durante cerca de 30 anos. Apesar de mesmo durante a sua carreira as suas obras atingirem elevados valores, o pintor nunca abandonou aquele espaço até à sua morte em 1992.

12. Para uma clara (e crítica) descrição do espaço após a deslocação do ateliê de Bacon, ver Getsy (2010) e também Wood (2005, 163-164).

13. Esta crítica aos modelos e lugares institucionais de produção e apresentação da arte foi muito explorada por Marcel Broodthaers, que estrategicamente usou o ateliê como meio de atacar o museu (Reijnders 2013, 152-155), entre outros autores.

14. Ver, por exemplo, a recente publicação Post Critical Museology: Theory and Practice in the Art Museum (Dewdney, Dibosa, e Walsh 2013).

\section{RESUMOS}

Este texto constitui-se como um passo para o entendimento do que hoje pode ser o ateliê de artista considerado no seu campo expandido, explorando ideias preliminares para a investigação em curso. Apesar de artistas como Daniel Buren ou Robert Smithson, no início dos anos 1970, terem declarado a extinção do ateliê ao evidenciarem um processo criativo no qual o espaço de criação seria parte integrante da obra e instaurando o que se viria a chamar uma era pós-estúdio, pretendo mostrar que, se entendido enquanto espaço e condição, o ateliê está sempre presente na génese e desenvolvimento do processo criativo, sendo um reflexo das tensões, avanços e retrocessos inerentes a esse processo. Com a expansão do conceito de ateliê alargaram-se também as suas modalidades na produção da arte contemporânea, permitindo novas e importantes relações e dinâmicas com outros dispositivos inerentes (ou não) ao meio artístico. 0 museu funciona, para muitos artistas contemporâneos, como um elemento de continuidade do ateliê, sendo muitas vezes ele mesmo o espaço preferencial de criação artística. É precisamente sobre essa perspetiva do museu como ateliê do artista que este artigo procura refletir, introduzindo alguns estudos atuais sobre o tema acompanhados de exemplos recentes. Em jeito de conclusão pretendo lançar pistas para uma futura discussão mais alargada sobre o modo como um estudo transdisciplinar sobre o ateliê pode contribuir para aprofundar o conhecimento da produção artística contemporânea, bem como da sua receção, documentação ou musealização. 
This paper is a step towards understanding the current concept of the artist's studio considered in its expanded field, exploring preliminary ideas for the writer's ongoing investigation. Although in the early 1970s, artists such as Daniel Buren or Robert Smithson declared the 'extinction' of the studio, thus promoting a creative process with place as an intrinsic part of the work, resulting in what would later be known as the post-studio era, I will argue that the studio, if understood as 'a space and a condition' is always present in the genesis and development of the creative process, reflecting its inherent tensions, advances and regressions. With the expansion of this concept of the artist's studio, its models in contemporary art production were also widened, allowing for new relations and dynamics with other devices from within or outside the art world. For many contemporary artists, the museum is an element of continuity from the studio, many times the preferred space for the creation of new artworks. It's precisely this perspetive of the museum as artist's studio that this paper intends to consider, introducing recent studies on the subject as well as recent examples. I thereby intend to suggest possible avenues for a future discussion regarding the contribution of a transdisciplinary study of the artist's studio to a greater knowledge of contemporary artistic production, as well as its reception, documentation or musealization.

\section{ÍNDICE}

Palavras-chave: Ateliê artista, processo artístico, exposição, museu arte contemporânea, musealização

Keywords: Artist studio, artistic process, exhibition, contemporary art museum, musealisation

\section{AUTOR}

\section{TERESA AZEVEDO}

Licenciada em História da Arte pela Faculdade de Letras da Universidade do Porto (2004) e mestre em Estudos Artísticos, com especialização em Estudos Museológicos e Curadoriais pela Faculdade de Belas Artes da mesma universidade (2008). Colaborou no projeto de inventário da obra do escultor Alberto Carneiro e foi investigadora no projeto Documentação de Arte Contemporânea (Instituto de História da Arte, Faculdade de Ciências Sociais e Humanas da Universidade Nova de Lisboa). É investigadora na linha de Museum Studies do Instituto de História da Arte (FCSH-UNL) e doutoranda em museologia na Universidade do Porto. Desenvolve investigação sobre ateliês de artista, documentação e musealização de arte contemporânea e processos criativos de produção artística.teresa.c.azevedo@gmail.com 